\title{
Supply-Demand Network of Steel Logistics: A New Research Perspective on Steel Logistics Resources Integration
}

\author{
Fan Yuqing*, Ju Songdong, Ding Jingzhi and Xu Jie \\ School of Economics and Management, Beijing Jiaotong University, Beijing, China
}

\begin{abstract}
At present, with the adjustment of the structure of the steel industry, the steel logistics industry is also engaged in integrating. Steel logistics resource integration is an important problem to be solved. Based on previous research on steel logistics resource integration, this paper proposes a new research perspective on steel logistics resources integration: supply-demand network of steel logistics. This paper analyzed the characteristics of supply-demand network of steel logistics, proposed connotation of steel logistics resources integration based on supply-demand network of steel logistics, which integrates supply organization and demand organization of steel logistics service as a whole network, restructuring and optimizing allocation of steel logistics resources by means of constructing steel logistics service supply chain, and integrating steel logistics service supply chain and steel products supply chain into an integrated steel supply chain. This new research perspective has great significance to expand the range and boundary of steel logistics resources and realize the linkage and win-win situation of logistics industry and steel industry.
\end{abstract}

Keywords: Logistics network, Resources integration, Steel logistics, Supply-demand relationship of logistics.

\section{INTRODUCTION}

Steel industry is an important and basic industry of the national economy. At present, there are some outstanding problems in steel industry, such as steel production capacity surplus and supply-demand contradiction. Since 2013, the government has promulgated a series of policy documents about merger and reorganization of steel enterprises and solution of steel production capacity surplus. With the adjustment of steel industry structure, steel logistics industry is integrating. Currently, steel logistics industry exhibits some outstanding problems, such as irrational allocation and uneven distribution of steel logistics resources. These problems restrict operation efficiency and benefit of steel logistics system and the whole steel industry. Therefore, steel logistics resources integration is particularly important. Based on previous research on steel logistics resource integration, this paper proposed a new research perspective on steel logistics resources integration: supply-demand network of steel logistics.

\section{LITERATURE REVIEW OF STEEL LOGISTICS RESOURCES INTEGRATION}

\subsection{Logistics Resources Integration}

At present, studies on logistics resource integration focus on three aspects.

\subsubsection{Mode and Mechanism of Logistics Resources Inte- gration}

Ma [1] analysed the integration of logistics resources and causes of problems, pointed out the need for logistics

*Address correspondence to this author at the Beijing Jiaotong University, Beijing, China; Tel: +86-138-10315487; E-mail: fyq0012@163.com resources integration, and proposed several modes of logistics resources integration: platform aggregation, capital interaction, information network, supply chain and exchange. Yang [2] analysed the present situation of logistics resources and the necessity of logistics resources integration, and proposed five different modes of logistics resources integration based on theory of industry life cycle, industrial convergence and transaction cost. These five modes are mergers and acquisitions, logistics strategic alliance, alliance of producers, logistics park and regional logistics alliance. $\mathrm{Wu}$ and Yuan [3] analyzed market structure and constraints of China's logistics industry, proposing three modes of logistics industry integration: mergers and acquisitions, alliances and clusters. Romano [4] tried to explain how logistics processes can be structured and controlled across supply networks by leveraging co-ordination and integration mechanisms, with consequences for strategic and operational choices for both the individual companies and the whole supply network. Rutner et al. [5] pointed out the impacts of the integrated logistics systems on electronic commerce and enterprise resource planning systems. Huang et al. [6] proposed logistics resource grid for grid service architecture, constructing a resource integration framework of logistics resource grid based on Globus Toolkit and Open Grid Services Architecture Data Access and Integration. Zeng [7] analysed approaches of regional logistics resources integration on regional logistics public information platform.

\subsubsection{Logistics Resource Allocation}

Logistics resources allocation is related to logistics resources integration. Most studies on logistics resources allocation focus on distribution and project management. Chantaravarapan et al. [8] studied the relationships between value-based allocation and resource allocation priorities. Huth 
and Mattfeld [9] studied the dynamic vehicle route in logistics network and the integration of resource allocation, propose an integrated approach, constructing a mathematical model. Maropoulos et al. [10] proposed a new theoretical framework for the overall planning of the logistics network integration.

\subsubsection{Supply Chain Integration}

There are many studies on supply chain integration. These studies focus on methods of integration and value added of integration. The studies on methods of integration focus on how to achieve information sharing and coordination between different organizations. Cousins and Menguc [11] proposed and tested a model on how buyers can use the concepts of supply chain integration and socialization to achieve improved supplier communication and operational performance. Yao [12] analysed thoroughly the characteristics of the supply chain resource integration in $4 \mathrm{PL}$ mode from a quantitative view, sets up an operational framework by conducting case studies of surveyed enterprises combined with the empirical analyses of the supply chain resource integration. Vaart and Donk $[13,14]$ discussed the concepts of integration, shared resources and buyer focuses. The concept of integration is discussed from different perspectives. And they also analyzed a case of shared resources, uncertainty and supply chain integration in the process industry.

\subsection{Steel Logistics Resources Integration}

At present, studies on logistics resource integration focus on three aspects.

\subsubsection{Construction, Reorganization and Optimization of Steel Supply Chain}

Wang [15] analysed the present situation of the domestic steel industry and the steel trade enterprises, proposed the development strategy to strengthen resources integration and enhance extension service capacity of steel supply chain by taking China Railway Material Corporation as an example. Jia [16] studied the agility of SLSSC from the perspective of the Supply-Hub of integrated logistics services, analyses the optimization of steel logistics service supply chain resources integration. Yin [17] established the brittleness factor system of the supply chain, conducts mechanism research on the origin of complex system brittleness of the iron and steel industry supply chain, constructing brittleness model of the iron and steel supply chains. Pottera et al. [18] concluded that although the steel supply chain has evolved between 1990 and 2001 towards an integrated structure, there are currently constraints imposed by organizational boundaries. Enrico et al. [19] constructed three different transportation networks to search for the best scenario that allows to supply the plant and to distribute all the finished products to final customers in the most efficient way.

\subsubsection{Merger, Reorganization and Integration of Steel In- dustry}

Zhao and Huang [20] analyzed integration and reorganization mode in domestic and foreign steel industry, propose that the integration of the reorganization of China steel industry should accelerate regional restructuring and deep integration. Wang and Wang [21] proposed that steel produc- tion service group is a new perspective of steel industry merger and reorganization. And it is an important way to improve the international competitiveness of China's steel industry. Pan and He [22] analyzed the development trend of steel industry and the major adjustment of steel enterprises in China, and put forward the corresponding solutions to the process of strategic reorganization and resource optimization in steel industry.

\subsubsection{Design and Optimization of Steel Production Logis- tics System}

Giannetti et al. [23] built an energy-based evaluation method of a reverse logistics network for steel recycling from two aspects of economy and environment. Seong and Suh [24] proposed the method of raw materials integrated management based on optimization and simulation to arrange delivery cycle and predict the stock level. Lundkvist et al. [25] optimized recycling logistics system of steel production enterprises by constructing a mixed integer linear programming model.

From the domestic and foreign related researches, it can be seen that the researches on steel logistics resources integration lack targeted studies, and the researches are not deep enough. Some other researches are repetitive.

At the same time, most perspectives of researches on logistics resources integration are from the perspective of logistics service provider. They are lack of thought which considers logistics supply side and demand side as a whole. Moreover, there are also few researches on the relationship between logistics supply side and demand side.

Therefore, from the viewpoint of the relationship between logistics supply side and demand side, this paper proposed a new research perspective on steel logistics resources integration: supply-demand network of steel logistics. This paper further analysed the connotation of steel logistics resources integration based on the new perspective.

\section{SUPPLY-DEMAND NETWORK OF STEEL LOGIS- TICS AND ITS CHARACTERISTICS}

\subsection{The Theory of Logistics Supply-Demand Network}

The theory of logistics supply-demand network has been developed from logistics network theory proposed by $\mathrm{Ju}$ et al. [26]. Logistics network is developed to meet the demand of logistics systematization and standardization and includes three organic parts of logistics organization network, logistics infrastructure network and logistics information network that form the modern logistics service network system. Logistics network theory suggests that resources integration is the inevitable trend of the development of modern logistics and logistics networking is an effective way to integrate logistics resources. Each user in user organization can get united services from many logistics organization and each node in logistics organization can provide integrated services for a large number of users.

Based on logistics network theory, Ding et al. [27] proposed logistics supply-demand network theory to solve the problems, such as timely matching of the logistics supply and demand, dynamic integration of the supply chain along with the changes of user requirements. This theory combines 
multiple perspectives of the "logistics-logistics service network-logistics user network-supply chain management", elaborates the relationship among three dimensions including logistics organization, logistics user organization and time, providing a new method to research on supply-demand relationship of logistics.

According to logistics supply-demand network theory, logistics services demand organization (user) can select logistics service from one or more logistics service supply organizations (logistics organization). Each logistics organization can serve for one or more users. Logistics service supply chain can be integrated according to user demands. Logistics supply-demand matching is relatively stable and temporary.

\subsection{Particularity of Supply-Demand Network of Steel Logistics}

According to logistics supply-demand network theory, organizations in the network are divided into two types, which are logistics service supply organization and demand organization. This is suitable for universal research on logistics supply-demand relation. This research found that steel logistics has more obvious particularities compared to universal logistics supply-demand relationship.

In this paper, supply-demand network of steel logistics highlights the following particularities.

\subsubsection{Dual Attributes of Some Nodes}

In the logistics supply-demand network, some nodes have dual attributes, which can both provide logistics service and demand logistics service in some cases. For example, some nodes in logistics user organization have logistics resources and can provide logistics service.

In the steel industry, this situation is more obvious. On one hand, steel production enterprises provide logistics services for downstream customers in steel supply chain by using storage resources and transportation resources. On the other hand, steel production enterprises outsource a part of logistics to the third logistics company.

According to "2012 China supply chain management report", 77\% steel enterprises transport products to customers and dealers through the third party logistics company, and $23 \%$ steel enterprises transport products through their own logistics organization [28]. In addition, on one hand, steel trade enterprises entrust the third party logistics company to provide logistics service. On the other hand, steel trade enterprises provide warehousing, distribution, processing and other services by steel logistics park.

Therefore, according to the complex situation of steel logistics supply and demand organization, the range of steel logistics integration should be expanded to meet the need of actual operation considering the dual attributes of some nodes.

\subsubsection{Dynamic Integration to Form Steel Logistics Service Supply Chain}

Logistics resources integration is a dynamic process which changes with the change of logistics service demands, in which scattered logistics resources belonging to different organizations restructure and optimize, and form logistics service supply chain. This dynamic characteristic is more significant in steel logistics.

Steel industry is a basic industry. The range of its user is wide and scattered, including automobile, real estate, equipment manufacturing and other end users, as well as all kinds of steel trade enterprises. In addition, steel production enterprises and users are unevenly distributed.

Therefore, the steel logistics demand has diversity and dynamically changing characteristics. It also requires the logistics service organization or the user to dynamically integrate to form steel logistics service supply chain.

\subsubsection{The Fusion of Product Supply Chain and Logistics Service Supply Chain}

Research on logistics supply-demand relationship helps to realize linkage development and win-win cooperation between the steel industry and logistics industry.

The logistics supply side and logistics demand side are involved in one network. One supply chain can form by integrating. Each supply chain is not only a product supply chain but also steel logistics service supply chain. It fully reflects the fusion of product supply chain and logistics service supply chain.

Under specified condition of steel raw materials and products in great quantities, the fusion is more significant.

\section{CONNOTATION OF STEEL LOGISTICS RE- SOURCES INTEGRATION BASED ON THE PER- SPECTIVE OF SUPPLY-DEMAND NETWORK OF STEEL LOGISTICS}

Based on the above characteristics, this paper proposed the connotation of steel logistics resource integration based on the perspective of supply-demand network of steel logistics, which is integrates supply organization and demand organization of steel logistics service as a whole network, restructuring and optimizing allocation of steel logistics resources by means of constructing and integrating steel logistics service supply chain and steel products supply chain into an integrated steel supply chain to meet the demand of steel logistics user and achieve linkage and win-win goal of supply organization and demand organization of steel logistics.

The connotation includes the following three points.

\subsection{Integrating Logistics Resources of the Whole Steel Logistics Supply-Demand Network}

The range and boundary of steel logistics resources are the premise of research on steel logistics resources integration. In steel logistics supply-demand network, some nodes have dual attributes, which can provide logistics service and demand logistics service in some cases. Based on the perspective of supply-demand network of steel logistics, the range and boundary of steel logistics resources are the whole steel logistics supply-demand network that includes supply organization and demand organization of steel logistics. 
4.2. Constructing Steel Logistics Service Supply Chain According to Demand, Realizing Steel Logistics Resource Sharing

With the promotion of the integrity and complexity of logistics service outsourcing, logistics organization forms a complete logistics service supply process through the mutual relationship between supply and demand of service process. The multi-stage supply-demand relationship constitutes the logistics service supply chain [29]. Based on the steel logistics supply-demand network, steel logistics resources integration is a process in which three parts including supply node, demand node and dual attribute node interact and the scattered steel logistics resources are dynamically restructured and allocated. The steel logistics resources realize sharing and the level of steel logistics service is enhanced through the steel logistics resources integration.

\subsection{Realizing the Linkage and Win-Win of Logistics Ser- vice Supply Organization and Demand Organization}

Based on steel logistics supply-demand network, the steel logistics supply and demand parties are in the same network. They open their own logistics resources to a certain extent. Through the steel logistics resources integration, on one hand, the steel logistics supply organization enhances the capacity of steel logistics service; on the other hand, the demand of steel logistics user can be met. And this promotes the linkage and win-win situation of logistics service supply organization and demand organization.

\section{SIGNIFICANCE OF THE NEW RESEARCH PER- SPECTIVE OF STEEL LOGISTICS RESOURCES IN- TEGRATION}

Steel logistics resources integration is logistics resources integration in the specific steel industry. It has both the general characteristics of logistics industry and the special characteristics of steel industry. Therefore, the new research perspective of steel logistics resources integration has important theory and practical significance.

\subsection{Expanding the Range and Boundary of Steel Logis- tics Resources Integration}

Usually the subject of logistics resources integration is of logistics service provider. Logistics resources integration optimizes the allocation of logistics resources dispersed in logistics supply organization. Based on steel logistics supply-demand network, the steel logistics service supply organization and the demand organization are a whole network. Logistics resources not only include the logistics resources of logistics service supply organization, but also include the logistics resources of logistics service demand organization. Based on the steel logistics supply-demand network, steel logistics resources integration and the scattered steel logistics resources are dynamically restructured and allocated. The steel logistics supply-demand network expands the range and boundary of steel logistics resources integration, which is from steel logistics supply organization to the steel logistics supply-demand organization.

\subsection{Contributing to Realize the Linkage and Win-Win of Logistics Industry and Steel Industry}

Based on the steel logistics supply-demand network, the steel logistics resources of supply-demand organization realize resource sharing. In the construction of the steel logistics service supply chain, steel products supply chain is also constructed at the same time. In the steel supply chain which integrates steel logistics service supply chain and steel products supply chain, logistics, business flow, capital flow and information flow operate effectively, and each party realize the win-win situation. Therefore, steel logistics resources integration based on the steel logistics supply-demand network is the effective way to realize linkage of logistics industry and steel industry.

\section{CONCLUSION}

At present, the steel industry is under restructuring, merger and reorganization. The logistics industry has developed rapidly, but there are some serious problems, such as scattered and closed logistics resources. Steel logistics resource integration is an important problem to be solved.

Based on previous research on steel logistics resource integration, this paper proposed a new research perspective on steel logistics resources integration: supply-demand network of steel logistics.

According to the new perspective, this paper analyzed characteristics of supply-demand network of steel logistics from three aspects: dual attributes of some nodes, dynamic integration to form steel logistics service supply chain, fusion of product supply chain and logistics service supply chain.

And then this paper proposed connotation of steel logistics resources integration based on supply-demand network of steel logistics, which is integrating supply organization and demand organization of steel logistics service as a whole network, restructuring and optimizing allocation of steel logistics resources by means of constructing steel logistics service supply chain, and integrating steel logistics service supply chain and steel products supply chain into an integrated steel supply chain.

This new research perspective has great significance to expand the range and boundary of steel logistics resources and realize the linkage and win-win situation of logistics industry and steel industry.

After making clear the new research perspective, further research still needs to be conducted on the mode, process and mechanism of steel logistics resources integration according to the actual situation of the enterprise and region.

\section{CONFLICT OF INTEREST}

The authors confirm that this article content has no conflict of interest.

\section{ACKNOWLEDGEMENTS}

This paper was supported by the National Natural Science Foundation of China (Grant No. 71102150). 


\section{REFERENCES}

[1] X. Ma, "Study on the mode of logistics resources integration in china”, Social Scientists, vol. 9, pp. 92-95, 2011.

[2] Y. Liu, Study on Logistics Resources Integration. Beijing Wuzi University: Beijing, 2007.

[3] Y. Wu, and P. Yuan, "Objectives and modes of china's logistics industry integration", Storage, Transportation and Preservation of Commodities, vol. 12, pp. 01-05, 2004.

[4] P. Romano, "Co-ordination and integration mechanisms to manage logistics processes across supply networks", Journal of Purchasing and Supply Management, vol. 9, pp. 119-134, 2003

[5] S. M. Rutner, B. J. Gibson, and S. R. Williams, "The impacts of the integrated logistics systems on electronic commerce and enterprise resource planning systems", Transportation Research Part E: Logistics and Transportation Review, vol. 39, pp. 83-93, 2003.

[6] C. Huang, B. Huang, and C. Li, "Research on resource integration framework of logistics resource grid", Computer Integrated Manufacturing Systems, vol. 5, pp. 630-635, 2005.

[7] Y. Zeng, "Research on public information platform and regional logistics resources integration", Science and Technology Management Research, vol. 4, pp. 125-126, 2007.

[8] S. Chantaravarapan, A. Gunal, and E. J. Williams, "On Using Monte Carlo Methods for Scheduling", Proceedings of the 2004 Winter Simulation Conference, vol. 1-2, , 2004, pp. 1870-1875.

[9] T. Huth, and D. C. Mattfeld, "Integration of vehicle routing and resource allocation in a dynamic logistics network", Transportation Research Part C: Emerging Technologies, vol. 17, no. 2, pp. 149162, 2009.

[10] P. G. Maropoulos, A. Kotsialos, and D. G. Bramall, "A theoretical framework for the integration of resource aware planning with logistics for the dynamic validation of aggregate plans within a production network", CIRP Annals - Manufacturing Technology, vol. 55, no. 1, pp. 483-488, 2006.

[11] P. D. Cousins, and B. Menguc, "The implications of socialization and integration in supply chain management", Journal of Operations Management, vol. 24, no. 5, pp. 604-620, 2006.

[12] J. Yao, "Decision optimization analysis on supply chain resource integration in fourth party logistics", Journal of Manufacturing Systems, vol. 29, no. 4, pp. 121-129, 2010.

[13] T. van der Vaart, and D. P. van Donk, "Buyer focus: Evaluation of a new concept for supply chain integration", International Journal of Production Economics, vol. 92, no. 1, pp. 21-30, 2004.

[14] D. P. van Donk, and T. van der Vaart, "A case of shared resources, uncertainty and supply chain integration in the process industry", International Journal of Production Economics, vol. 96, no. 1, pp. 97-108, 2005.
[15] W. Li, "Giving full play to regional advantages to integrate resources effectively and enhance extension service capacity of steel supply chain”, Railway Purchase and Logistics, vol. 4, pp. 61-63, 2013.

[16] R. Jia, A Study on Service Supply Chain Agility of Steel Logistics Based on Supply-Hub. Huazhong University of Science and Technology: China, 2011.

[17] R. Yin, Research on Brittleness Management of Iron and Steel Supply Chain Based on Complex System Theory. Ocean University of China: China, 2011.

[18] A. Potter, R. Masonb, M. Naim, and C. Lalwani, "The evolution towards an integrated steel supply chain: A case study from the UK", International Journal of Production Economics, vol. 89, pp. 207-216, 2004.

[19] E. Briano, C. Caballini, R. Mosca, and R. Revetria, "Using logistic redesigner (Lo.R.D.) software for designing and simulating a steel supply chain", WSEAS Transactions on Systems, vol. 9, no. 2, pp. $125-135,2010$

[20] L. Zhao, and X. Huang, "Comparative analysis of integration and reorganization mode in domestic and foreign steel industry", Truth Seeking, vol. 10, pp. 40-43, 2010.

[21] X. Wang, and H. Wang, "Steel industry merger and reorganization based on the vertical steel industry chain", Metallurgy Management, vol. 4, pp. 50-53, 2010.

[22] K. Pan, and J. He, "Trend of Integration Model in China's Steel Industry", Contemporary Economics, vol. 2, pp. 70-72, 2012.

[23] B. F. Giannetti, S. H. Bonilla, and C.M.V.B. Almeida, "An emergybased evaluation of a reverse logistics network for steel recycling", Journal of Cleaner Production, vol. 46, pp. 48-57, 2013.

[24] D. Seong, and M.S. Suh, "An integrated modelling approach for raw material management in a steel mill", Production Planning and Control, vol. 23, no. 12, pp. 922-934, 2012.

[25] K. Lundkvist, M. Larsson, and C. Samuelsson, "Optimisation of a centralised recycling system for steel plant by products, a logistics perspective", Resources, Conservation and Recycling, vol. 77, pp. 29-36, 2013.

[26] S. Ju, J. Xu, and W. Bian, "Putting forward and research on logistics network theory", Journal of Beijing Jiaotong University(Social Sciences Edition), vol. 4, pp. 22-26, 2005.

[27] J. Ding, S. Ju, Xujie, and W. Bian, "Three-dimensional characteristics concerning supply-demand and relationship of logistic", Journal of Beijing Jiaotong University (Social Sciences Edition), vol. 11, pp. 38-44, 2012.

[28] P. Shao, 2012 China Supply Chain Management Report. Wealth Press, Beijing, 2013.

[29] A. Cui, W. Liu, and X. Zhang, "Theoretical framework of LSSC," Journal of Shanghai Maritime University, vol. 29, pp. 1-6, 2007.

Received: September 16, 2014

Revised: December 23, 2014

Accepted: December 31, 2014

(C) Yuqing et al.; Licensee Bentham Open.

This is an open access article licensed under the terms of the Creative Commons Attribution Non-Commercial License (http://creativecommons.org/licenses/by-nc/4.0/) which permits unrestricted, non-commercial use, distribution and reproduction in any medium, provided the work is properly cited. 